\title{
RESEARCH
}

\section{From Aristotle to Contemporary Biological Classification: What Kind of Category is "Sex"?}

\author{
Stella Sandford \\ Kingston University London, UK \\ S.Sandford@kingston.ac.uk
}

This paper examines the nature of the categories of 'male' and 'female' as classificatory groupings, via an examination of this question in Aristotle's zoology and metaphysics. Tracing the use of Aristotle's logical categories of 'genus' and 'species' in his zoological works and contrasting this with the use of the terms in contemporary taxonomy, the paper demonstrates that 'male' and 'female' are, in a significant sense, unclassifiable. Although Aristotle has no generic concept of 'sex' at his disposal, the paper shows how many English translations of his works introduce 'sex' as if in answer to the question of the nature of the categories of male and female. The paper then argues that the generic concept of sex covers over the problem of the classification of male and female in both Aristotle and contemporary biology (including botany, mycology and bacteriology), by introducing a classificatory genus ('sex') that does not in fact explain anything but rather (in its trans-species generality) needs explaining.

Keywords: Sex; male/female; Aristotle; biology; taxonomy; classification

All living organisms that have been scientifically recorded or studied are named according to the relevant international code for nomenclature. Naming and denoting a taxonomical classification are two sides of the same coin. Although the definitions and epistemological status of the standard taxonomical categories (species, genus, family, order, etc.) are not uncontested, their use is standardized and clear and the hierarchical relations between them are unambiguous. We know what it means to say that German chamomile is a plant species, that bluebirds constitute a genus and that Vertebrates are a subphylum of the phylum Chordata. The terminal taxon of biological nomenclature is usually the species (for example Homo sapiens) or the subspecies (for example the domestic dog, Canis lupus familiaris). Distinctions lower than this (for example, the division of dogs into breeds) are not taxonomical distinctions. They are variations, whose intra-(sub-)species differences may be physically relatively large but are inessential in relation to the (sub-)species definition. Varietal differences are 'accidents', in the traditional philosophical sense; the colour of a plant variety, for example, cannot either define or divide the species. 
Bearing this in mind, the question arises: what sort of a difference is sex difference in relation to these categories? When we categorise individuals or groups of organisms as 'male' or 'female,' what is the relationship between this categorisation and the formal taxonomical classification of species, subspecies, and so on? That is, what kind of categorisation is identification as 'male' or 'female' in relation to the kind of categorisation we see in biological taxonomy? What kind of category is 'sex'?

In part 1 of this study, these questions are addressed via an examination of aspects of Aristotle's zoological works, specifically his use of the logical terms genos (genus) and eidos (species) in those works, and his brief discussion (in the Metaphysics) of the male-female difference in relation to species definition. This route is suggested by the fact that Aristotle's terms are at the basis of modern biological taxonomy. But more importantly, this study of Aristotle highlights (in part 2) the problematic nature of the classificatory categories of male and female, especially as (contrary to expectations fostered by most English translations) he has no generic category of 'sex' (part 3). Finally, the paper shows how this problem endures in contemporary systems of biological classification and concludes that the generic concept of 'sex' is not an answer to the question of the nature of the categories of male and female, but is itself a problem that needs to be addressed.

\section{Genus and species: logic and nature}

Aristotle's zoological works distinguish and compare various animals and various parts of animals utilising the terminology, and to some extent the methods identified, in his logical works. Most obviously, Aristotle works on animals - especially History of Animals and Parts of Animals - use the logical terms 'genus' (genos), 'species' (eidos) and 'differentia' (diaphora) to identify essences and (in principle) to supply definitions according to the rules set out in the logical works. Mutatis mutandis, this terminology is the basis for all modern systems of biological classification, or the basis of biological systematics itself. However, when the terms 'genos' and 'eidos' are employed in Aristotle's zoological works they do not correspond to the taxonomical categories of 'genus' and 'species' in modern natural history and biology. ${ }^{1}$ Modern taxonomical categories (for example, species, genus, family, order, class, phylum, and so on) allow for the classification of living organisms in a hierarchical system; that is, they designate rank or level in a hierarchic classification. The entities that are thus classified are 'taxa'; they are what Ernst Mayr $(1991,20)$ calls the 'concrete objects of zoological classification' - thus the species 'German chamomile' (Matricaria chamomilla), the genus 'bluebirds' and the subphylum 'vertebrates' are all taxa at different ranks. ${ }^{2}$ In modern taxonomy what is, for example, identified as a species group could never in principle also be a genus. Of course, DNA analysis of a particular organism group might require its reclassification in a different species group; similarly, further study of a subspecies might cause it to be reclassified as a species. But no taxon can be simultaneously be a subspecies and a species, or as a species and a genus. ${ }^{3}$ The categories of 'species' and 'genus' refer each taxon to what Pierre Pellegrin $(1986,68)$ calls a fixed position, designating a constant level of reality, within the modern system of classification. ${ }^{4}$

\footnotetext{
${ }^{1}$ We are so apt to be misled by this that there is a case for not translating genos and eidos as 'genus' and 'species'. Lennox (2001: 127 and passim) argues this, preferring 'kind' and 'form'.

2 Mayr, 1991: 20, 21. See also Minelli 1993: 3-4; Simpson 1961: 19: 'A taxon is a group of real organisms recognized as a formal unit at any level of a hierarchical classification.'

3 Taxonomists might argue about whether a given group of organisms constitute a single species or a group of subspecies, as recently has happened with giraffes. During the period of argument some may refer to a given group as a subspecies while others do not recognise it as such. But the point is that the argument is about whether they are one or the other; all parties concerned presuppose that they cannot be both. Even where genera are monospecific the single species in that group is still classified as a species.

${ }_{4}^{4}$ See also Pellegrin 1985 and 1987.
} 
In the Categories and Posterior Analytics Aristotle explains that a species is defined through its genus and its differentia (what came to be known as definition per genus et differentiam). What a species is, is determined by the genus to which the species belongs and what differentiates that species from all other species of the same genus. Because the genus is more general than the species, answers to the question 'What is it?' are always more instructive when the species is given. To the question 'What is this?', the answer 'It is a horse' is more instructive than 'it is an animal,' though the horse does belong to the genus 'animal'. Aristotle's theory of definition looks for what commentators now call the 'infima species,' the lowest species - that species which is not a genus for anything else, for example, 'human'.

Following these rules, Aristotle's zoological works sometimes use the terms 'genus' and 'species' when grouping and comparing animals, but the terms are not taxonomic in the sense set out above. Genos and eidos are not taxonomic categories in a system of classification for Aristotle because what is for the purposes of one discussion treated as a genos containing several eide may well elsewhere be treated as an eidos of a different genos; similarly, what is at one time an eidos may elsewhere be treated as a genos. Thus here 'classification' refers to looser, often ad hoc, groupings of living organisms. ${ }^{5}$

Although Aristotle does not (and probably did not aim) to construct any systematic classification, his application of the logical categories of genus and species in the zoological works sometimes results in groupings that we still today recognise as taxa, albeit at different taxonomical ranks: "By "genus" I mean, for instance, Bird or Fish; for each of these is subject to difference in respect of its genus, and there are many species of fishes and of birds' (HA I, 1, 486a23-5). ${ }^{6}$ Further, Aristotle distinguishes between different kinds of comparison and different kinds of difference and fairly consistently casts these as 'generic' and 'specific' differences. These differences are, or can be, sorted according to the distinction, set out at the beginning of the History of Animals, between differences that are a matter of degree and those that compare things only analogously. For example, the difference between firm and soft flesh, or between a short and a long beak, are differences of degree, of the more and the less, and 'as a general rule, most parts and those that go to make up the bulk of the body are either identical to one another or differ from one another in the way of contrariety and of excess and defect. For the more and the less may be represented as excess and defect.' However, 'there are some animals whose parts are neither identical in form nor differing in the way of excess and defect; but they are the same only in the way of analogy, as, for instance, bone is only analogous to fish-bone, nail to hoof, hand to claw, and scale to feather; for what the feather is in a bird, the scale is in a fish' (HA I, 1, 486b14-21). In Parts of Animals Aristotle says that analogy compares features across genera, whereas differences of degree obtain within a genus: 'For all kinds [genōn] that differ by degree and by the more and the less have been linked under one kind [heni genei], while all that are analogous have been separated' (PA I, 4, 644a17-19). ${ }^{7}$ In regards to the functionality of animal parts, Aristotle distinguishes those activities (and their corresponding parts) that i) are common (koinas) to all animals; ii) are generic (kata genos), that is, "belong to animals whose differences among each other are seen to be in degree [kath' huperochēn]'; and iii) those that are specific (kat' eidos): "For example I speak generically of "bird" but specifically of "man" and of every animal that

\footnotetext{
${ }^{5}$ We may distinguish between classification according to a taxonomic system and ad hoc, even nonce, classification (for example, a group of people might be classified for the purposes of a competition according to the sports that they play - as footballers, tennis players, cricketers, etc.)

${ }^{6}$ In-text references to Aristotle's History of Animals (HA) give the Book, Chapter and Bekker numbers. Unless otherwise stated, all translations are Thompson's (Aristotle 1984a).

7 In-text references to Aristotle's Parts of Animals (PA) give the Book, Chapter and Bekker numbers. Unless otherwise stated, all translations are Balme's (Aristotle 1992).
} 
has no differentia in respect of its general definition. What they have in common some have by analogy, some generically, some specifically' (PA I, 5, 645b21-30).

However, throughout Aristotle's zoological works disparate groupings of animals are also referred to as gene in what we must presume to be a more colloquial sense; Aristotle most frequently uses the term 'genos' in a non-technical sense, in its most general meaning as 'kind.' When we look at the various ways in which animals are grouped in Aristotle's zoological works, we see that the logical principle of the genus-species relation is more frequently applied where the words themselves are not used, for example in distinguishing sanguineous from non-sanguineous animals, and dividing each of these groups into oviparous and viviparous, and dividing each of these groups further until we reach the infima species for the purposes of this division, which is something that looks like a modern common or folk-biological species: human, horse, pig, and so on. Logically, many of these could be further subdivided for other purposes such as to produce a different infima species - for example 'pig' might be divided into its domesticated and wild 'species.' Aristotle sometimes also identifies genera (in the broadest sense) of animals according to various distinctions which, although they find no equivalent in modern taxonomy, are recognisable in popular and popular-scientific contexts - for example, the distinction between land-living and water-living animals. We also find some of those very familiar and still-widely used groupings which may not have a place in modern taxonomy (for example, 'tree') or whose taxonomy may be at odds with the popular usage (for example, 'reptile'). ${ }^{8}$

In sum, Aristotle's classifications of animals often compare and differentiate groups according to a logical-scientific criterion that distinguishes between generic-type and specific-type differences, and these sometimes identify what we might recognise as taxa (bird, fish, human), but they more often pick out generic groups for the purposes of comparing particular parts of various animals or particular properties. To this end any given animal might be found in different generic groups, with different congeners, at different times ${ }^{9}$ (which is not possible in modern taxonomy, where everything has just one place). Distinctions and comparisons made according to this logical-scientific criterion must, in principle, bear analysis according to the definitions of the categories of genus and species and the relations between them set out in the logical works.

\section{The logic of 'male' and 'female'}

In Aristotle's zoological works the frequency with which animals are grouped, compared and distinguished according to the categories 'male' and 'female,' is striking. Aristotle also notes similarities and differences between males and females across and within various generic groups and within species, including the human. In History of Animals II, for example, Aristotle notes that

with regard to the breasts and generative organs, animals differ widely from one another and from man [anthrōpon]. For instance, the breasts of some animals are situated in front ... and there are in such cases two breasts and two teats, as is the case with man [anthrōpon] and the elephant ... the elephant has two breasts in the region of the axillae; and the female elephant [ $\bar{e}$ thēleia] has two breasts insignificant in size ... the males [hoi arrenes] also have breasts, like the females [hai thēleiai], exceedingly small (HA II, 1, 500a19-23).

\footnotetext{
8 The taxonomic group of reptiles includes birds, although birds are not popularly thought of as reptiles.

9 Producing the kind of classification that Simpson (1961: 13-4) calls a 'key', as opposed to a hierarchy.
} 
He goes on to compare the breasts and teats of the bear, sheep, cow, dog, pig, leopard, lion, camel and horse. In describing the male generative organs, he distinguishes those animals whose organs are external (like man and horse) from those whose are internal (like the dolphin) (HA II, 1, 500a33-500b1). Considering blood, he distinguishes viviparous from oviparous animals (the former being 'more abundantly supplied with blood'); he compares humans to all other animals (humans have the finest and purest blood); mentions the respects in which all sanguineous animals are alike (blood palpitates in the veins, is developed first in the heart, etc) then compares all males of all sanguineous species with all females ('the blood in the female is thicker and blacker than in the male') and the female of the human species with all other sanguineous females (the former being most richly supplied with blood and having the most copious menstrual discharge) (HA III, 19, 520b10-521a29).

In History of Animals when Aristotle discusses the differences between male and female animals in general (where 'animal' functions as a genus) or the differences between male and female within a more restricted genus the differences are overwhelmingly differences of degree. ${ }^{10}$ For example, in red-blooded, non-oviparous animals with feet, the male is larger and longer-lived; in all animals

the upper and front parts are better, stronger, and more thoroughly equipped in the male than in the female ... the female is less muscular and less compactly jointed, and more thin and delicate in the hair - that is, where hair is found; and where there is no hair, less strongly furnished in some analogous substance (HA IV, 11, 538b2-10).

In Parts of Animals, Aristotle also characterises the differences between males and females in this way: males are stronger, more choleric; females have the same parts as males but in an lesser degree, sometimes vanishing into not having at all. Thus, for example, animals are only furnished with offensive and defensive weapons to the extent that they need or can use them: 'this explains why stags have horns, while does have none; why the horns of cows are different from those of bulls' (PA III, 1, 662a1-3). ${ }^{11}$ But what kinds of comparison, in the context of what kinds of classification, are actually being made here?

Logically, in these examples, 'females' are identified as a species within the genus 'redblooded, non-oviparous animals with feet,' or within the genus of 'animal' itself. The remark about horns in Parts of Animals indicates that females are identified (logically) as a species within the genus 'horned animal' or even in this example as sub-species within the species 'deer' and 'bovine'. The remark about hair in History of Animals indicates that the group 'females' is also being constituted across genera (the genus of those with hair and the genus or genera of those with something analogous to hair). So if, as Aristotle says, 'what they [animals] have in common some have by analogy, some generically, some specifically', what kind of having-in-common is being-female when males and females are compared in this way? How, according to Aristotle's own definitions and accounts of the logical categories and their application to animals, can 'male' and 'female' fit in?

Perhaps the most obvious suggestion would be that male and female are species of each kind of animal considered as a genus, or more generally species of the genus 'animal', remembering

${ }^{10}$ As HA I, 1, 486b14-17 would lead us to expect: 'as a general rule, most parts and those that go to make up the bulk of the body are either identical with one another, or differ from one another in the way of contrariety and of excess and defect.'

11 Ogle's translation; Aristotle 1984b. For similar comparisons see also HA IX, 1, passim. In HA IX, 1, 608a 22-27, it is said that 'In all kinds in which there are the female and the male, nature has established much the same difference in the character of the females as compared to that of the males [especially the viviparous quadrupeds...] For the character of the females is softer, and quicker to be tamed, and more receptive of handling, and readier to learn.' (Balme's translation). 
that 'species' is first and foremost a logical, not a natural, category for Aristotle. But in the Metaphysics Aristotle rules this out quite explicitly. In Book VII (Z) of the Metaphysics, which contains the famous discussion of the meaning of 'being' (to on) and 'substance' (he ousia), 'essence' (to einai) is identified as one of the meanings of 'substance' (Met. VII, 3, 1028b3335). ${ }^{12}$ The 'essence' of each thing is then said to designate 'that which it is said to be per se' or in itself (to ti en einai hekastou ho legetai kath' auto). The 'formula' (ho logos) of the essence of each thing defines the term without repeating the term in that definition (Met. VII, 4, 1029b12-23). But as the categories other than substance all necessarily combine with substance, the question arises as to whether there is a formula of the essence of each of those compounds (for example, the compound in which a quality is predicated of a substance, as in 'white man'). Aristotle answers that there is not, strictly speaking, a formula for each of these, as the essence is what something is, a 'this,' (hosper tode ti), and only a substance is a 'this', not a compound predicating something of a substance. A definition is an account of something 'primary,' something that cannot be further specified and which does not involve one thing being predicated of another: 'hence essence will belong to nothing except species of a genus [tōn genous eidōn], but to these only; for in these the predicate is not considered to be related to the subject by participation or affection [pathos], nor as an accident [sumbebēkos]' (Met. VII, 4, 1030a5-14). ${ }^{13}$

But there is a class of compound formulae in which the qualification belongs to the subject by virtue of the subject, or belongs to the subject per se, in itself, kath' auto. These are formulae which involve terms or entities that are not 'simple' but 'coupled'. For example, according to Aristotle, 'snubness' is a term compounded of 'nose' and 'concavity'. Unlike 'white' - which is an accident that can be explained apart from any subject to which it happens to be attributed - 'snub' belongs to 'nose' per se, because it cannot be explained apart from 'nose,' that is, apart from its subject. ${ }^{14}$ In the same way, according to Aristotle, 'male' and female belongs to 'animal' per se and 'equal' belongs to 'quantity' per se, because they cannot be explained apart from their subject (Met. VII, 5, 1030b15-27).

Here, Aristotle mentions male and female without saying anything about the difference between them, or even that they are different - he merely refers to one and then to the other as illustrations of 'coupled' terms. This is hardly surprising, as the point of this section is to determine what can and cannot be defined, not to define male and female. In Book X (I), however, in the context of a discussion of what it means to be 'other in species' Aristotle does speak of the difference between male and female as belonging to 'animal' per se. If 'other in species' means to be the same in genus but a contrariety, and if male is contrary to female, why, he asks, are male and female animals not other in species? For this difference "belongs to "animal" per se, and not as whiteness or blackness does; "male" and "female" belong to it qua animal.' (Met. X, 9, 1058a29-34) Marguerite Deslauriers (1998) cites this and the example from Book VII as evidence that Aristotle's position is that male and female are non-essential and yet non-accidental attributes of the genus animal - that is, they do not belong to the definition of animal ('animal' can be explained apart from 'male' and 'female'), but they are also not merely accidental. In Book XIII (M) Aristotle calls those attributes peculiar to animals qua male or qua female 'in-itself accidents' (Deslauriers's translation of

${ }^{12}$ In-text references to Aristotle's Metaphysics (Met.) give the Book, Chapter and Bekker numbers. Unless otherwise stated, all translations are Tredennick's (Aristotle 1933a and 1933b).

13 Later Aristotle also says that 'essence ... will belong primarily and simply to substance, and secondarily to other things as well' (Met. VII, 4, 1030a29-32); 'the primary and unqualified definition, and the essence, belong to substances. It is true that they belong equally to other things too, but not primarily.' (Met. VII, 4, 1030b5-7).

${ }^{14}$ In Ross's translation (Aristotle 1984e): 'it is not by accident that the nose has the attribute either of concavity or snubness, but in virtue of its nature [kath' autēn]'. 
sumbebēke kath' auta), or 'peculiar attributes' (idia pathē). In Ross's translation: 'Many properties attach to things in virtue of their own nature as possessed of some such property; e.g. there are attributes peculiar to the animal qua female or qua male, yet there is no female nor male separate from animals' (Met. XIII, 3, 1078a5-8) (Ross 1965). ${ }^{15}$ The point in its simplest form is that, because male and female have no separate essence they are not (cannot be) different species.

To summarize: it is clear that, for Aristotle, male and female cannot be considered as species of 'animal' in general or of any particular animal. But what then is the nature of the classificatory grouping when females are compared to males in general or in relation to particular kinds of animals? This looks very much like a species grouping within a genus, but apparently it cannot be this, logically or naturally, as this would, even for the purposes of an ad hoc comparison, treat males and females as essentially different from one another, which makes no sense when they are, precisely, males and females of the same animal.

Could it be, then, that males and females should be considered as different logical genera? In the examples above being-female or being-male cannot be a generic having-in-common according to Aristotle's definition, because in these examples the genus is higher than beingfemale (for example, 'red-blooded, non-oviparous animals with feet' or 'animal' or 'horned animal'); that is, it is not that females within the group 'female' are being compared with each other. Elsewhere, Aristotle does compare the females of different species and of different genera, qua females, with each other (and the same is true with males). These comparisons are sometimes quite general, but more often compare specific animals with others in relation to their characteristics and habits and their generative organs. ${ }^{16}$ Logically, this seems to treat 'the female' and 'the male' as different genera, each containing an equal and identical number of species. But this not only contradicts Aristotle's basic characterisation of a genos in his Categories (Aristotle 1963: 3, 1b16-18) (because 'the differentiae of genera which are different and not subordinate to one another are themselves different in kind', which is not the case if male and female are genera) it also treats the female and the male of each kind of animal as a different species, belonging to a different genus, which, as we have seen, is unacceptable to Aristotle. ${ }^{17}$ It also contradicts the characterisation of what it is to differ in genos in Met. X, 4, 1055a7-8: 'things which differ in genus have no means of passing into each other, and are more widely distant, and are not comparable', which is obviously not the case

${ }^{15}$ The purpose of the example here is to draw a parallel with the objects of the study of mathematics ('Hence there are also attributes which are peculiar to things merely qua lines or planes', although 'lines' and 'planes' have no separate existence. Met. XIII, 3, 1078a8-9) That is, in mathematics it is permissible - indeed it is best - 'to take that which does not exist in separation and consider it separately.' (Met. XIII, 3, 1078a21-23) Thus male and female here exemplify those things which have no separate existence but which we are yet permitted to study separately. The context is a critique of Plato's theory of Ideas; that is, 'male' and 'female', like 'line' and 'plane', can be studied as separate without positing them as existing as Ideas.

16 See, for example, HA VI, 18, 572a10-572b25 and HA II, 8, 502b22-24: 'The generative organs of the female [ape] [he thèleia] are similar to those of a woman [gunaiki]; those of the male are more like a dog's than a man's are.' (Peck's translation.) Aristotle sometimes uses the gendered forms of the nouns 'male' and 'female' (ho arren, he thè $l u$ ) and sometime the neuter forms of both (to arren, to thēlu). (He often also uses adjectival forms.) I cannot discover any principled rule governing the uses of the different forms.

17 See Aristotle Posterior Analytics II, 13, 96b15-16 (1984d): 'When you are dealing with some whole, you should divide the genus into what is atomic in species - the primitives'. Dividing the genos 'female' would ultimately give the different kinds of female animals as 'atomic' species: female human, female, dog, female horse and so on. But Met. X, 9 1058a29-34 rules this out. Topics I, 5 102a31-32 (Aristotle 1984c) defines genos as 'what is predicated in what a thing is of a number of things exhibiting differences in kind [Genos d'esti to kata pleionōn kai diapherontōn tōi eidei en tōi ti esti katēgoroumenon].' If male and female were genera the female horse would be essentially more like the female ape than it is like the male horse, which Aristotle obviously does not hold. 
with male and female, which appear in the same species. ${ }^{18}$ Basically, male and female are not sufficiently different to count as different genera. Further, Topics IV, 1, 121a5-9 stipulates that 'the genus ought to fall under the same division as the species; for if the species is a substance, so too should be the genus, and if the species is a quality, so too the genus should be a quality'. (Aristotle 1984c) There is no way to understand the relation between 'female' and the various 'female animals' according to this rule (that is, it does not work to say either that both are substances or that both are qualities).

In History of Animals (I, 6, 490b17-19), having remarked that some genera (for example birds, fishes, cetaceans) are extensive, having within them other subdivisions, Aristotle notes also that other animals do not fit into any large group: 'in them one species [eidos] does not comprehend many species [eidē]; but in one case, as man [anthrōpōs], the species is simple, admitting of no differentiation [ouk echon diaphoran]'. And yet 'man' (and other animals) are, explicitly, divided into the male and the female (for example, HA I, 15, 19: 'These, then, are the parts common to the male and the female'). This seems to mean that 'male' and 'female' name differences between animals, but a difference that cannot count as one of the 'differentiae' (diaphorai), where 'differentiae' are those differences that, in relation to the genus, define a species. ${ }^{19}$ According to Aristotle in his Categories (5, 3a40-1) 'differentiae ... are predicated both of the species and of the individuals'; as 'female' cannot be predicated of any species, such that all members of the species are female, 'female' cannot be a differentia. ${ }^{20}$ Differentiae should also not divide a species (PA I, 3, 643b1-9), but 'male' and female precisely do, without being accidental divisions such as 'black' and 'white'.

Perhaps, one would be tempted to say, the problem of the classificatory status of male and female could be avoided if we understood Aristotle to be treating each male and each female animal being compared as an individual, not as a species or a genus. But the basis of their comparison in this context just is their being grouped together as either 'male' or 'female', and it is the status of just this grouping that is at issue. If it is right (as commentators increasingly agree that it is $)^{21}$ that genos and eidos do not function as fixed taxonomical terms in Aristotle's zoological works, the question of the classificatory status of the groupings of male and female concerns not whether Aristotle presents 'male' and 'female' as 'species' or 'genera' in the modern, natural historical-biological meaning of these terms. ${ }^{22}$ The question is whether there is any classificatory level, any permutation of genos, eidos and differentia, at or in which the groups 'male' and 'female' make sense according to Aristotle's own lights. Is there anywhere in his collection of ad hoc classifications that it makes sense to think of 'male' and 'female' as either a genos, an eidos or a differentia in his senses of these terms? And it

${ }^{18}$ For Pellegrin (1986: 56) the fundamental definition of genos is 'that enclosure beyond which there is nothing but pure otherness, but within which, in its very unity, the diversity of eide is produced.' But we cannot say that 'female' and 'male' are absolutely other, because they belong together within each species: male and female human, male and female dog, and so on.

19 Topics VI, 4, 141b25-26 (Aristotle 1984c): 'a correct definition must define a thing through its genus and its differentiae'; see also Topics VI, 6, 14419ff; Cat. II, 1b18-19: 'footed, winged, acquatic, two-footed, are differentiae of animal'.

${ }^{20}$ See also PA I, 3 643a28-29: 'one should divide [eti diairein] by what is in the being, and not by the essential accidents [sumbebēkosi kath' auto]'; Met. VII, 12, 1037b4-1038a12.

21 See, for example, Lennox 2001: 40, 127-9, 177; Furth 1987: 49; Balme 1987a: 72, 79; Balme 1987b: $296-7$. Atran (1990: 113-14) opposes Pellegrin's view, arguing that Aristotle does aim to produce a complete classification, based on existing folk taxonomy. But: i) Atran does not take issue with Pellegrin's claims about the use of the concepts of genos and eidos; and ii) Pellegrin agrees with Atran that Aristotle makes frequent use of folk (or common-sense) groupings.

22 See Deslauriers 1998: 163 (fn 13): "Although Aristotle does not give us his reason for thinking that male and female cannot be different species, presumably it is because the sexual union of male and female "naturally" and usually (although not always) produce offspring of the same species.' 
seems that there is not. This means not just that we cannot see what kind of groupings 'male' and 'female' are, but also that the relation between the distinction and the category that it divides is obscure. Although this problem is not described in exactly this way in Aristotle's zoological works, it seems plausible that the discussion in the Metaphysics is evidence of his awareness of it.

\section{Male and female without 'sex'?}

So how is it that male and female are, nevertheless, grouped? Pellegrin argues that Aristotle's zoology does not aim at definitions of animals but presumes (as a methodological convenience) the different species that have an 'immediate" obviousness' and that must therefore 'be found at the beginning of the process of biological research.' This includes recourse to the layperson's 'spontaneously ousiological' designation of species. (Pellegrin 1986: 39, 45) The 'very extensive genera of animals [gene de megista zōōn], into which other subdivisions fall' (HA I, 6, 490b7-8) - for example, 'birds' and 'fishes' - which Aristotle associates with the popular names of things seem also to be common-sense categories of this kind. Perhaps 'male' and 'female' are, similarly, 'common-sense' designations in $H A$ and $P A$, groups or terms presumed for the purposes of the treatises but not themselves the subject of analysis. 'Male' and 'female' would then be gene only in the most general and non-Aristotelian sense - a sense not able to bear close inspection or analysis in Aristotelian terms. This would explain why, despite the frequent use of the word 'genos' in many contexts, Aristotle never explicitly refers to males or females as a genos in the scientific context of $H A$ and $P A .^{23}$

This is especially significant, when we remember that 'genos' is the ancient Greek term that is usually translated as 'sex' in translations of Plato and other classical authors - as, for example, in Lee's translation of Plato's phrase 'to tōn andrōn kai to tōn gunaikōn genos' (Plato 1987: 454d8), 'men or women as a sex'. 'Sex' is given as one of the meanings of 'genos' in Greek lexicons; but there is no specific word for 'sex' (in the sense of 'sex difference') in classical Greek; there is no specific word to name the difference between male and female. Even though Aristotle never refers to groups of men or woman as a 'genos,' twentieth-century translators of Aristotle's works on animals (including Generation of Animals) into English have tended to make free use of the English word 'sex' and phrases such as 'sex difference' and 'the two sexes' when translating some of Aristotle's claims about male and female animals. This practice tends to be carried over into commentaries on Aristotle, both in the general literature by major figures in Aristotle scholarship and the more recent specialised literature on male and female. ${ }^{24}$ For example (many more could have been chosen):

'Esti d'ouden arren kai thēlu en tois monimois' (HA IV, 11, 537b24-5): 'In animals that live confined to one spot there is no duality of sex' (Thompson), or 'In stationary animals there is no division of sex' (Peck; Aristotle 1970).

'Tōn dè tēn genesin echontōn aposuggenōn zōōn en hois men autōn esti to thēlu kai to arren...' (HA V, 1, 539a26-27): 'In those animals where generation takes place from animals of the same kind, where there are the two sexes...' (Peck; Aristotle 1965), or 'In

\footnotetext{
${ }^{23}$ Balme (1987a: 79) notes that Aristotle's flexible usage of genos 'is only possible because he is not attempting a classification system but applies the concept of genos with its forms freely to all levels of generality and to all objects of definition, whether whole animals or parts.' But not, we can now add, to 'male' and 'female'.

${ }^{24}$ For the latter see, for example, McGowan Tress 1992; Nielsen 2008; Kosman 2010; Connell 2016.
} 
animals where generation takes place from animals of the same kind, wherever there is duality of sex...' (Thompson; Aristotle 1984a).

'eisi de diaphorai tou thēleos kai arrenos kai en tois anaimois, hosa autōn echei tautēn tēn enantiōsin' (GA I, 2, 716a35-b2):25 'There are also differences between male and female in those of the bloodless creatures which have this opposition of the sexes' (Peck; Aristotle 1942), or 'There are corresponding differences of male and female in all the bloodless animals also which have this division into opposite sexes' (Platt; Aristotle 1984f).

'Phaneron oun hoti archē tis ousa phainetai to thēlu kai to arren' (GA I, 2, 716b10-11): 'Clearly, then, the distinction of sex is a first principle' (Platt; Aristotle 1984f), or 'It is clear, then, that "the male" and "the female" are a principle' (Peck; Aristotle 1942).

'Epei de to men dunatai to d'adunatei ekkrinai to perittōma katharon'(GA IV, 1, 765b3637): 'Now as the one sex is able and the other unable to secrete the residue in a pure condition...' (Peck; Aristotle 1942), or 'Now since the one sex is able and the other is unable to reduce the residual secretion to a pure form...' (Platt; Aristotle 1984f).

The introduction of 'sex' into translations of Aristotle's discussions of male and female is thus arguably a misleading modern intervention. It introduces a classificatory genos in a quasi-taxonomical sense (with 'male' and 'female' as its species) that is alien to the Aristotelian texts and obscures the classificatory problem of male and female or obscures the extent to which the distinction between male and female is an intriguing problem in natural history. The identification of this problem is not a criticism of Aristotle's zoology; rather, it highlights something of particular interest. It allows us to see that this problem endures, well beyond Aristotle's texts, in contemporary biological taxonomy and in philosophy, as we may still ask: what is the relation of the distinction between male and female to any possible system of natural classification, and how is this related to philosophical categorisation?

Linguistically, at least, the positing of the logical genus 'sex' allows us to present the difference between male and female in ways not available to Aristotle (or indeed Plato ${ }^{26}$ ); but it is not clear that this is very different to the kind of common-sense presupposition of male and female that we see in Aristotle's $H A$ and $P A$. It stands in as an answer to the question, 'what kind of classificatory categories are male and female?' through the assertion that they are sex categories, but the concept of sex does not allow us to say much more about the commonality of femaleness or maleness across genera (including animals, plants, fungi, algae and bacteria) beyond various stipulative definitions that, on analysis, always presuppose 'male' and 'female', and often quite contentiously.

Arguably, modern biological taxonomy, although it acknowledges the difference between male and female as 'forms, ${ }^{27}$ also does so only in a common-sense way. This may be true despite the fact that scientific definitions of male and female are remote from the everyday (probably primarily morphological) understanding of the division of male and female.

${ }^{25}$ GA refers to Aristotle's Generations of Animals (Aristotle 1942 and 1984f).

26 See Sandford 2010, especially Chapter 1.

27 See, for example, Mayr 1991: 48. Also Mayr 1991: 1: 'Each species may exist in numerous different forms (sexes, age classes, seasonal forms, morphs, and other phena).' 
In Margulis and Sagan (1986: 195), for example, the definitions rely on an understanding of anisogamy (where mating types have gametes of different sizes): "the smaller of a pair of gametes is dubbed "male". Male sex cells are so designated, however, not only because of their smaller size but because of their propensity to move on their own.... The practical definition of male is simply an organism (gamont) that produces moving, relatively small gametes (or microgametes) itself. The term female, by general definition, usually refers to those gametes which stand still or those gamonts which produce sedentary gametes.') Note that the definitions refer to both gametes and the organisms carrying or producing those gametes. That it is apparently possible to distinguish between 'male' and 'female' unicellular organisms by 'the presence of a protein on the surface of the undulipodia (as in ciliates) or the existence in one position but not in another of a transposable piece of DNA (as in yeast),' that is by 'miniscule molecular differences', (Margulis and Sagan 1986: 198-9) shores up the sense of the gap between scientific discourse and the vernacular. However, if, as is the case, those different 'mating types' in much of the natural world frequently change into their opposite and back again; if non-dimorphic differentiation is also extremely frequent and hermaphroditism is the rule rather than the exception in huge groups of organisms, like plants; if the idea of sex can only be applied to fungi by postulating thousands of different sexual forms or thousands of different combinations of male and female, might we also not be tempted to say that the male/female dichotomy is a remnant of the popular understanding of sex in the scientific definitions? ${ }^{28}$ When the donor and the recipient of fragments of DNA in 'bacterial sex' (i.e. non-reproductive, non-meiotic genetic recombination) are called 'male' and 'female' it seems little different from the gendering of electric plugs and sockets; ${ }^{29}$ that is, the folk presumption of sex binarism provides the conceptual framework and vocabulary in both cases. Perhaps, then, 'male' and 'female', understood dichotomously, are folk biological terms like 'tree', 'reptile', 'quadruped' and 'worm', but ones that nestle still at the heart of biological science?

To a certain extent this may be true of many of the categories that comprise biological systematics. This is partly why the contemporary adequacy of the biological taxonomy that grew out of Linnaeus's system of classification is hotly contested. Minelli (1993: 13), for example, explains how molecular phylogenetics suggests that the 'terminal taxa' (the most basic units of classification) may not be 'species' but genomes- after all, the very idea of a 'species' is pre-evolutionary. Other of the standard taxonomical categories are similarly contested. ${ }^{30}$ However, the idea of a difference in 'form' between male and female seems not to receive anything like the same theoretical attention. 'Form' is a very broad and amorphous, nontaxonomic category - Mayr (1991: 48) calls it a 'neutral term' - that includes 'varieties', stages of development (the embryo is a 'form' different to the adult 'form') and stages of metamorphosis (larval 'forms' as opposed to chrysalis 'forms'). In these other examples it seems to be a primarily morphological category; this is also suggested by Mayr's characterisation of male and female as different 'phena' (1991: 56). In that case the same phenom may appear in different forms (neonate female, adolescent female, adult female), indicating that 'form' is really just a convenience term for distinctions that have already been picked out, not a term

28 For a similar argument see Bivins 2000.

${ }^{29}$ Margulis and Sagan 1986: 54: "The donor is conceptually the "male", because the genes travel from "him" to be received by "his" partner, conceptually a "female." ... The donor rounds up his mate and forces "his" genes into "her".' What determines this gendered conceptuality?

30 Minelli 1993: 139: 'During the 1980s and 1990s, one of the most restless areas of systematics has been the arrangement of higher taxa. Ultrastructural and molecular studies have caused and are still causing a continual revision of concepts'. 
that might explain anything about those distinctions. As these 'forms' are easiest to pick out in large vertebrate mammals the suspicion once again arises that this vernacular dimorphic form, having been picked out, is read back into the rest of the animal kingdom and also applied to plants, fungi, algae and bacteria.

In conclusion, male and female cannot, in principle, be part of biological taxonomy. ${ }^{31}$ So when we group organisms as 'male' and 'female' across all the orders of living organisms what kind of commonality is it that we ascribe to them? Are 'male' and 'female' scientific, philosophical or popular categories? The evidence points to their popular status, even at the heart of modern biology. Perhaps, de facto, 'male' and 'female' are essentially folk biological terms that we still use to categorise the natural world, a possibility that has significant implications for contemporary sexual politics.

An examination of Aristotle's work allows us to see this problem most clearly, both because he explicitly raises the problem of the nature of the division of the 'species' into male and female, and because (contrary to the standard translations) he does not have the generic concept of 'sex'. We can then also see more clearly that the problem remains in contemporary scientific and popular classifications. Although we may now say that male and female are 'sexed' forms, in doing so we merely add a nominal genus ('sex'), and it is precisely this nominal genus that is in question. The investigation in this paper brings us to the conclusion that this generic category of 'sex' is not an answer to the problem of the commonality of 'male' and 'female' across, not just genera, but kingdoms of life; it is instead an historical and conceptual problem which requires further work.

\section{Acknowledgements}

This research was made possible by a Major Research Fellowship from the Leverhulme Trust ('Sex Difference in Natural History', MRF 2017-006).

\section{Competing Interests}

The author has no competing interests to declare.

\section{References}

Aristotle. 1933a. Metaphysics Books I-IX. Trans. Hugh Tredennick. Cambridge, MA/London: Harvard University Press.

Aristotle. 1933b. Metaphysics Books X-XIV, Oeconomica, Magna Moralia. Trans. Hugh Tredennick. Cambridge, MA/London: Harvard University Press.

Aristotle. 1942.Generation of Animals. Trans. A. L. Peck. Cambridge MA: Harvard University Press. DOI: https://doi.org/10.4159/DLCL.aristotle-generation_animals.1942

Aristotle. 1963.Categories and De Interpretatione. Trans. J. L. Ackrill. Oxford: Clarendon Press. Aristotle. 1965. History of Animals, Books 1-3. Trans. A. L. Peck. Cambridge, MA: Harvard University Press.

Aristotle. 1970. History of Animals, Books 4-6. Trans. A. L. Peck. Cambridge, MA: Harvard University Press.

Aristotle. 1984a. History of Animals. Trans. D'A. W. Thompson. In The Complete Works of Aristotle, edited by Jonathan Barnes, Volume One. Princeton, NJ: Princeton University Press.

\footnotetext{
31 See Simpson 1961: 18-19. Aristotle's translator Peck also pointed this out in 1965, in his Introduction to Aristotle's History of Animals (Aristotle 1965: xxix).
} 
Aristotle. 1984b. Parts of Animals. Trans. W. Ogle. In The Complete Works of Aristotle, edited by Jonathan Barnes, Volume One. Princeton, NJ: Princeton University Press. DOI: https://doi. org/10.1515/9781400835843-025

Aristotle. 1984c. Topics. Trans. W. A. Pickard-Cambridge. In The Complete Works of Aristotle, edited by Jonathan Barnes, Volume One. Princeton, NJ: Princeton University Press. DOI: https://doi.org/10.1515/9781400835843-008

Aristotle. 1984d. Posterior Analytics. Trans. Jonathan Barnes. In The Complete Works of Aristotle, edited by Jonathan Barnes, Volume Two. Princeton, NJ: Princeton University Press.

Aristotle. 1984e. Metaphysics. Trans. W. D. Ross. In The Complete Works of Aristotle, edited by Jonathan Barnes, Volume Two. Princeton, NJ: Princeton University Press.

Aristotle. 1984f. Generation of Animals. Trans. A. Platt. In The Complete Works of Aristotle, edited by Jonathan Barnes, Volume One. Princeton, NJ: Princeton University Press.

Aristotle. 1992. De Partibus Animalium I and De Generatione Animalium I. Trans. D. M. Balme. Oxford: Clarendon.

Atran, Scott. 1990. Cognitive Foundations of Natural History: Towards an Anthropology of Science. Cambridge: Cambridge University Press.

Balme, D. M. 1987a. "Aristotle's Use of Division and Differentiae". In Philosophical issues in Aristotle's Biology, edited by Alan Gotthelf and James G. Lennox. Cambridge: Cambridge University Press.

Balme, David. 1987b. "Aristotle's Biology was not Essentialist". In Philosophical issues in Aristotle's Biology, edited by Alan Gotthelf and James G. Lennox. Cambridge: Cambridge University Press.

Bivins, Roberta. 2000. "Sex Cells: Gender and the Language of Bacterial Genes". In Journal of the History of Biology 33: 113-139. DOI: https://doi.org/10.1023/A:100477990 2860

Connell, Sophia. 2016. Aristotle on Female Animals: A Study of the Generation of Animals. Cambridge: Cambridge University Press. DOI: https://doi.org/10.1017/CBO97813164 79766

Deslauriers, Marguerite. 1998. "Sex and Essence in Aristotle's Metaphysics and Biology". In Feminist Interpretations of Aristotle, edited by Cynthia A. Freeland, 138-167. PA: Pennsylvania University Press.

Furth, Montgomery. 1987. "Aristotle's Biological Universe: An Overview". In Philosophical issues in Aristotle's Biology, edited by Alan Gotthelf and James G. Lennox. Cambridge: Cambridge University Press.

Kosman, Aryeh. 2010. "Male and Female in Aristotle's Generation of Animals". In Being, Nature, and Life in Aristotle: Essays in Honour of Allan Gotthelf, edited by James G. Lennox and Robert Bolton. Cambridge: Cambridge University Press.

Lennox, James G. 2001. Aristotle's Philosophy of Biology: Studies in the Origins of Life Sciences. Cambridge: Cambridge University Press.

Margulis, Lynn, and Dorion Sagan. 1986. Origins of Sex: Three Billion Years of Genetic Recombination. New Haven/London: Yale University Press.

Mayr, Ernst. 1991. Principles of Systematic Zoology. New York: McGraw-Hill.

McGowan Tress, Daryl. 1992. "The Metaphysical Science of Aristotle's Generation of Animals and His Feminist Critics". Review of Metaphysics 46: 307-41.

Minelli, A. 1993. Biological Systematics: The State of the Art. London: Chapman \& Hall.

Nielsen, Karen M. 2008. "The Private Parts of Animals: Aristotle on the Teleology of Sexual Difference". Phronesis 53: 373-405. DOI: https://doi.org/10.1163/156852808X338337 
Pellegrin, Pierre. 1985. "Aristotle: A Zoology without Species". In Aristotle on Nature and Living Things: Philosophical and Historical Studies, edited by Allan Gotthelf. Pittsburgh, PA: Mathesis Publications/Bristol Classics Press.

Pellegrin, Pierre. 1986 [1982]. Aristotle's Classification of Animals: Biology and the Conceptual Unity of the Aristotelian Corpus. Trans. Anthony Preus. Berkeley: University of California Press.

Pellegrin, Pierre. 1987. “Logical Difference and Biological Difference: The Unity of Aristotle's Thought". In Philosophical issues in Aristotle's Biology, edited by Alan Gotthelf and James G. Lennox. Cambridge: Cambridge University Press.

Plato. 1987. Republic. Trans. Desmond Lee. London: Penguin.

Ross, David. 1965. Aristotle's Prior and Posterior Analytics. Oxford: Clarendon.

Sandford, Stella. 2010. Plato and Sex. Cambridge: Polity.

Simpson, George Gaylord. 1961. Principles of Animal Taxonomy. New York/London: Columbia University Press/Oxford University Press.

How to cite this article: Sandford, Stella. 2019. "From Aristotle to Contemporary Biological Classification: What Kind of Category is "Sex"?" Redescriptions: Political Thought, Conceptual History and Feminist Theory 22(1): 4-17. DOl: https://doi.org/10.33134/rds.314

\section{Submitted: 05 November 2019 Accepted: 05 November 2019 Published: 03 December 2019}

Copyright: (c) 2019 The Author(s). This is an open-access article distributed under the terms of the Creative Commons Attribution 4.0 International License (CC-BY 4.0), which permits unrestricted use, distribution, and reproduction in any medium, provided the original author and source are credited. See http://creativecommons.org/licenses/by/4.0/. 